


\title{
FROM THE POSSIBLE PREDOMINUM OF TECHNOLOGY TO THE CRISIS OF THE HUMAN REASON
}

\author{
By Lizdaribeth Hernández
}

\begin{abstract}
Reason must be the faculty that provides the principles of knowledge a priori; with it, the human being has the capacity of rise, with autonomy to judge about itself and its surroundings without delegating its own criteria to anyone. This writing glimpses the near danger that the human will experience unless he makes continuous use or exercises his superior faculties of the soul."Sapere Aude" is the Latin locution that urges the human being to think for himself; however, is man conscious that there must be a frivolity of thought that delays his society? Among so many adversities, technology with its progress result disturbing if its dominance reins over the will and thought of man; However, intuition must be key to placing this in a reality where one can have objective conscious of what exists. The technological advances are innovations that alter reality in a positive and negative way according to its purpose. How to do in a society where machines are being created to match human consciousness, with the purpose of they exist to make less effort to the faculties of the human being and provide more comfort to this? Up to what point is technology a means and not an end, up to what will man be an end and not become an instrument of technology? It is important to determine that human reason should not be underestimated or imprisoned for the comfort that a futuristic society can provide. Self-knowledge must prevail today and always, and it to be linked to the leadership of a conscience that obeys to a fair society, which issues judgment and criticism, that has individual responsibility, and that reaches its age of majority as soon as it dares to know.
\end{abstract}

Keywords: Human Reason, Soul Faculties, Human Being, Society, Technology. 


\title{
DEL POSIBLE PREDOMINIO DE LA TECNOLOGÍA A LA CRISIS DE LA RAZÓN HUMANA
}

\begin{abstract}
RESUMEN
La razón ha de ser la facultad que proporciona los principios del conocimiento a priori; con ella el ser humano tiene la capacidad de elevarse, con autonomía para juzgar acerca de sí mismo y de lo que le rodea sin delegar a nadie su propio criterio. Este escrito vislumbra el cercano peligro que experimentará el humano sino hace uso continuo ni ejercita sus facultades superiores del alma. "Sapere Aude" es la locución latina que exhorta al individuo a pensar por sí mismo; sin embargo, ¿es el hombre consciente de que ha de existir una frivolidad de pensamiento que atrasa su sociedad? Entre tantas adversidades, la tecnología con su avance resulta un tanto perturbadora si su dominio impera sobre la voluntad y pensamiento del hombre; empero, la intuición ha de ser clave para situar a este en una realidad donde se puede tener consciencia objetiva de lo que existe. Los avances tecnológicos son innovaciones que alteran la realidad de manera positiva y negativa según sea su finalidad. ¿Cómo sobrevivir en una sociedad donde las máquinas están siendo creadas para igualar la consciencia humana, con el propósito de disminuir el esfuerzo a las facultades del ser humano y proveer más comodidad a este? ¿Hasta qué punto la tecnología es un medio y no un fin, y hasta qué punto el hombre será fin y no se convertirá en instrumento de la tecnología? Es importante determinar que la razón humana no debe ser subestimada ni encarcelada por la comodidad que pueda proporcionar una sociedad futurista. El autoconocimiento debe prevalecer hoy y siempre, y ser vinculado con el liderazgo de una consciencia que obedece a una sociedad justa, que emite juicio y crítica, que posee responsabilidad individual, y que alcanza su mayoría de edad tan pronto como se atreva a saber.
\end{abstract}

Palabras Claves: Razón Humana, Facultades del alma, Ser Humano, Sociedad, Tecnología. 


\section{DEL POSIBLE PREDOMINIO DE LA TECNOLOGÍA A LA CRISIS DE LA RAZÓN HUMANA}

Imagínese a un hombre atado de manos y pies, con una venda en los ojos y con los oídos cubiertos, no pudiendo estos percibir sonido; supóngase que esa persona ha sido desprovista de una regular temperatura, extremas y oscilando entre altas y bajas; sospéchese sobre un sujeto intervenido psicológicamente por un paradigma sin fundamentos morales, para ser exactos, un tanto anarquistas. Imagínese que ese sujeto ante de ser atado de manos y pies y vendado ha observado como la naturaleza ha sido derrotada y destruida por la ignorancia, soberbia y vanidad de otros hombres. Imagínese una sociedad donde la mente humana ha sido subyugada por la inteligencia artificial a causa del mal uso hacia esta.

¿Se Visualiza tal ilustración? Al parecer se reconoce una descripción un tanto distorsionada de lo que debería ser el humano en una sociedad equilibrada; no obstante, esto es una exageración muy cercana a la decadencia del ideal de humanidad, en cuanto al sujeto como ser sensible y razonal, a saber, como hombre de sociedad. Una distópica imagen del ser desvanecido en un tiempo y un espacio alarmante, donde las facultades no están nutridas porque no hay vida ni belleza en la naturaleza para percibir y sentir, ni consciencia para discernir en el procede, ni juicio e intuición que conceda una imagen acertada de la realidad.

La decadencia de la sociedad -sea cual sea- no es apresurada solamente por la alienación y enajenación que en ella hay, sino más bien, por el desinterés intelectual de parte de los hombres que subestiman la difícil pero importante tarea de la razón: El Autoconocimiento. La razón es madura cuando es capaz de barrer las arrogancias infundadas por consciencias dominadoras que persiguen una moralina, estafando a las consciencias más frágiles, claro está, solo si estas son débiles de presupuestos. Cuando la razón alcanza la mayoría de edad y el autoconocimiento es superior a la voluntad de los que alienan, la primera se prepara como un juez con claras bases morales que refuta inmediatamente ofertas engañosas; así la razón se convierte y actúa como expresa Immanuel Kant en su Crítica de 
la Razón Pura (1781) en un tribunal donde se instituyen máximas que respaldan la voluntad acorde a un ejemplar proceder.

¿Existe Frivolidad de pensamiento en nuestra época? Esta interrogante procede insistentemente en la reflexión humana, muchos tienen una respuesta y propuesta válida para derribar dicha frivolidad, mientras que otros se esmeran por prosperar con un pensamiento futurista que puede sustraer un poco aquella magia con la que proceden las facultades superiores del alma. Predecir si la sociedad avanza hacia un correcto camino es tarea difícil para aquellos a quienes solo le sirve especular, dado que son seres finitos faltos de inmortalidad; no obstante, no se necesita vivir dos siglos para suponer que algún error del presente traerá consecuencias en el futuro. Saber diferenciar la novedad en contraposición con el fetichismo por lo tecnológico, es rendirse fácilmente hacia lo que produce menos esfuerzo físico y mental según sea la alienación del hombre por lo ficticio y artificial.

Si el hombre es un todo, ¿Por qué va desprendiéndose progresivamente de los elementos que compone esa totalidad? El ser va hacia el futuro alejándose de lo que le invita a pensar, reflexionar y de por sí hacer crítica, de tal manera el humano empieza a ser desnudado y desprovisto de ese todo que le complementa, tal cual como el sujeto que se describe al inicio de este escrito. La razón humana no tiene porque perseguir un destino singular, ya que el hombre siempre anda en búsqueda del conocimiento, un ejemplo de ello ha de ser el interés del individuo por conseguir saciar sus especulaciones en el ámbito metafísico.

Las adversidades existen, la ignorancia también y la alienación es el hogar más cálido para aquellos que no ejercitan su intelecto. La crítica hace juicio y este a su vez es conocimiento, y cada conocimiento suma experiencia y presupuestos en el proceder del ser humano. Cuando la razón humana es acosada por las adversidades entonces se limita a la facultad de desear; pero cuando aquella no resbala en estas, entonces se eleva cada vez más exigiendo su propia naturaleza: La libertad y el conocimiento. 
En sentido kantiano, podemos alcanzar a conocer las cosas como fenómenos, pero esto solo es posible si una parte de nuestra esencia concibe la realidad como una imagen que alerta a la intuición. El ser humano tiene noticia objetiva de lo que existe mediante la intuición, ya sea empírica, intelectual, sensible o sensible pura. La consciencia de que algo existe en nuestra realidad y pensamiento, y que se amolda a un espacio y tiempo determinado nos da indicios de que concebimos una realidad sin tantas alteraciones.

La realidad es una dimensión representativa y figurativa de lo que existe de acuerdo a la subjetividad de cada sujeto; con ella la intuición como facultad cognoscitiva superior se eleva para centrar al individuo en una especie de verdad temporal-espacial; de hecho, a través de ella el ser puede captar qué situaciones empiezan a alterar, aliviar, o entorpecer abruptamente su bienestar en la sociedad, reflejo de ello pueden ser los avances tecnológicos que constituyen una gran evolución dentro del mundo, pero también una amenaza para el ejercicio pleno de las facultades del espíritu del hombre.

El ser humano se atrasa en la sociedad cuando no se atreve a saber, ni a liderar su propias emociones y preceptos, como consecuencia, la sociedad no avanza y sus habitantes se muestran menos justos, dependientes, sin autonomía y sin responsabilidad individual. "Sapere Aude" es la locución latina divulgada por Kant en contestación a la interrogante ¿Qué es la Ilustración? y promovida por los académicos, pero menos practicada y ejercitada por los seres humanos a lo largo de toda la historia. Tener el valor de usar la propia razón es enfrentarse al tenebroso abismo de la tiranía, corrupción, enajenación y alienación, es un desprenderse de ataduras, vendas y pensamientos fetichistas cautivadores pero nocivos para el avance de la sociedad y de los habitantes que se realizan en ella.

"Sapere Aude" como máxima exhorta al hombre a pensar sin delegar en otros su propio juicio; no obstante, en el presente el abuso de la tecnología o su desmesurado uso ha traído como secuela que el hombre deje de atreverse a pensar porque considera que ya existen máquinas que lo pueden hacer por él. La época tecnológica se arraiga cada vez más, verbi gratia: Existen producciones inteligentes que procesan comandos, ejecutan movimientos, y 
que poseen habilidades sumamente codiciadas por los humanos. En cuanto a fuerza, la tecnología aventaja al hombre, porque a lo largo de los años la mente humana se ha encargado de diseñar aparatos que le sirvan como una extensión de su fuerza; siendo así, aquella se hace notar como una ayuda cuando el ser humano la domina para su propio beneficio. El dilema en cuanto a la tecnología surge cuando el sujeto abusa de esta misma, ya sea, al querer robotizarse desfigurando su esencia humana en una producción artificial, o, cuando se hace dependiente de las invenciones tecnológicas, peligro que incrementará la esterilidad de las capacidades y habilidades del hombre.

El protagonismo de la tecnología en la sociedad actual vislumbra cuan funcional y creativa es la mente humana; empero, es de temer que en una sociedad futurista el hombre sea dominado por una inteligencia artificial que probablemente se desprenderá de las órdenes suministradas por los individuos. Posiblemente esto suceda en muchos siglos o solo quede como una mera suposición, aunque es evidente que el individuo se esmera cada vez más por dejar en manos de la inteligencia artificial muchas de las acciones que fácilmente la mente humana puede realizar.

El ser humano es un ser social y racional, además ha sido creado como la criatura más capacitada, competente para discernir, pensar, y hacer juicio; es fin en sí mismo y eco de sus propias acciones. Al ser el hombre un ente dotado de facultades no debe este eludir lo que es inherente a su razón: Alzarse con autonomía para juzgar acerca de sí mismo sin confiar su juicio y crítica a cualquier otro individuo o entidad artificial. Todos los conocimientos comienzan por los sentidos, los primeros luego pasan al entendimiento y terminan en la razón. Todo ese proceso que funciona como un engranaje sitúa al hombre como heredero del conocimiento universal que debe preocuparse por su evolución y ascenso en la sociedad. Cuando todas las facultades superiores del alma se ejercitan según su aplicación, entonces el ser humano alcanza la mayoría de edad como expresaba Immanuel Kant (1724-1804).

Entre la facultad de conocer y la facultad de desear, sirve como punto de convergencia la facultad sentir ya sea placer o dolor; es decir, el juicio (Facultad de sentir) funciona como 
concepto intermediario entre el entendimiento (Facultad de conocer) y la razón (Facultad de desear), dicha cohesión entre facultades posibilita el recorrido de la razón pura a la razón práctica; la primera en conformidad con las leyes de la naturaleza y la segunda en conformidad con la libertad (fin último). La inteligencia humana a diferencia de la inteligencia artificial lleva plena ventaja sobre la última. Ha de ser solo el ente racional y social el que posee el más elevado compendio de facultades, mismas que hacen a este una criatura sagaz y eminente por encima de la agudeza y fuerza de la inteligencia artificial. Solo la mente humana puede dar juicio sobre la naturaleza y el arte; sumado, solo el hombre es poseedor de razón y por lo tanto el único que puede dar uso del órganon de esta misma: La síntesis.

El disfrute y servicio que puedan proveer los avances tecnológicos a la sociedad actual deben ser mesurados y gestionados por la mente humana, misma que sabrá categorizar las labores de la inteligencia artificial para el beneficio del sujeto social. Los avances tecnológicos tienen mucho que aportar a todas las sociedades que integran al mundo; por ello, deben estos ser encaminados a la asistencia del pensamiento humano, acorde con las necesidades de la naturaleza y a merced del descubrimiento de nuevos conocimientos en el ámbito científico y artístico. 